Doi: $\underline{\text { dx.doi.org/10.17921/2525-5320.2016.274-280 }}$

\title{
EU SOU O ESCRITOR DO WHATSAPP: A TECNOLOGIA A FAVOR DO DESENVOLVIMENTO DE COMPETÊNCIAS
}

\author{
Nilson Douglas Castilho* - UTFPR \\ Alessandra Simone Martins Munhoz Garcia* - UTFPR \\ Palavras chave: Tecnologia. Competência.Aprendizagem.
}

\section{INTRODUÇÃO}

Tecnologia. Termo que permeia o homem em diversas situações do cotidiano. Hoje, o indivíduo sem um aparelho com vários aplicativos e sem acesso à Internet, ou que não domina o mínimo uso dessas ferramentas, torna-se obsoleto. Isso acontece, uma vez que o ser humano produz linguagens o tempo todo e leva os outros à ação por meio disso, e claro, o meio mais procurado e utilizado para produção de linguagens é a tecnologia.

A tecnologia é tão importante na relação humana que ela não se limita a laboratórios e indústrias. Para Bastos (1998) ela é um modo de produção, que faz uso de todos os instrumentos, invenções e artifícios, por isso, é também uma maneira de organizar as relações sociais, especialmente no que diz respeito ao advento das famosas redes sociais. Além do mais, Arocena (2004) complementa que a tecnologia tem multiplicado e transformado qualitativamente o poder de produzir e destruir, de curar e depredar, de ampliar a cultura dos seres humanos e de gerar riscos para a vida, sendo que este poder está distribuído de forma desigual.

Tendo em vista essa situação, a escola tem um papel fundamental na formação dos alunos quanto ao uso da tecnologia. Encontrar funcionalidade para o que é visto em sala de aula e desenvolver competências imprescindíveis para a inserção do sujeito na sociedade é a função da escola atual. Para Rodrigues (1992, p.28):

[...] educação não pode ficar à margem deste fenômeno (a tecnologia), cuja consequência direta reflete na escola, visto que a sua principal função, é preparar e elevar o indivíduo ao domínio dos instrumentos culturais,

\footnotetext{
*E-mail: ncastilho@colegiosmaristas.com.br

*E-mail: asgarcia@colegiosmaristas.com.br
} 
intelectuais, profissionais e políticos, garantir, ainda, que a cultura, a ciência e a técnica não sejam propriedades exclusivas das classes dominantes.

Dessa forma, recorrer aos novos aplicativos e recursos midiáticos pode proporcionar aos educandos experiências que promovam a aquisição de diversas habilidades e conhecimentos necessários para resolver situações-problema, sem deixar de lado os conceitos aprendidos na escola. Para Zabala (2010) é preciso que as práticas e sequências didáticas contemplem três tipos de conteúdo: conceituais, procedimentais e atitudinais. Os conteúdos conceituais referem-se aos conceitos e conhecimentos teóricos dos diversos componentes curriculares; por sua vez os conteúdos procedimentais estão no nível das ações a serem tomadas pelos alunos durante uma prática, como ler, inferir e traduzir; e por último, os conteúdos atitudinais relacionam-se aos comportamentos e atitudes desenvolvidos pelos alunos, a fim de serem sujeitos com papel ativo em sociedade promovendo a solidariedade, a alteridade, entre outros.

Tendo como base à influência da tecnologia na vida do homem moderno e as concepções sobre a prática educativa, criou-se o projeto Eu sou o escritor do Whatsapp. Em suma, ele envolveu a produção de textos argumentativos por meio do aplicativo whatsapp e da plataforma Blackboard (um ambiente virtual de aprendizagem) com alunos dos oitavos e nonos anos do Ensino Fundamental II de uma escola particular da cidade de Londrina, Paraná. A seguir, serão expostos o contexto de aprendizagem e as etapas do trabalho em consonância com os pressupostos teóricos que serviram como base para a escolha dos procedimentos a serem adotados.

\section{DESENVOLVIMENTO}

\section{Etapas do trabalho e concepções teóricas em torno do processo}

Os PCN sugerem que no Ensino Fundamental devem ser trabalhados os fundamentos para a construção da opinião por meio da tipologia do âmbito da argumentação. É um grande obstáculo para os alunos vencerem, uma vez que estão completamente acostumados com textos narrativos. Sendo assim, é de fundamental importância o papel do professor na apreensão de competências que envolvem a capacidade crítica do ser humano.

Antes de tudo, é preciso mostrar a funcionalidade na construção e leitura dos gêneros argumentativos. Textos de opinião fazem parte do uso cotidiano da língua. A 
todo momento expressam-se opiniões a respeito de diversos assuntos, dos mais corriqueiros aos mais complexos e polêmicos. Dessa forma, é necessário colocar o aluno em contato com os diversos gêneros de textos de opinião. Assim, estaremos levando em conta o que dizem os Parâmetros Curriculares (1988, p.24):

\begin{abstract}
Sem negar a importância dos textos que respondem a exigências das situações privadas de interlocução, em função dos compromissos de assegurar ao aluno o exercício pleno da cidadania, é preciso que as situações escolares de ensino de Língua Portuguesa priorizem os textos que caracterizam os usos públicos da linguagem, propiciando uma aprendizagem significativa, e ao mesmo tempo, prazerosa.
\end{abstract}

A primeira etapa do trabalho consistiu na apresentação de diversos gêneros de textos argumentativos. Depois, os alunos deveriam dizer o que conheciam a respeito daqueles gêneros, se já haviam tido contato com eles alguma vez, fazendo assim, de acordo com Zabala (1998), um levantamento do conhecimento prévio do aluno, levando-o a levantar hipóteses, fazer suposições e descobrir qual o grau de envolvimento deles nas suas reações à mediação do professor. Assim, os conteúdos procedimentais dessa etapa não são mera rotina, mas um instrumento para resolver as situações colocadas.

Por meio de questionamentos, os alunos foram percebendo quais as características comuns entre os textos apresentados, e junto ao professor criaram uma ficha com os elementos estruturais de um texto de opinião: Introdução, Desenvolvimento e Conclusão. Depois de uma análise criteriosa desses elementos e da leitura de diversos modelos de texto, fomos para a parte prática.

Já com os conceitos bem claros, por meio de análise de textos envolvendo situações-problema, os alunos deveriam produzir textos ou trechos de textos argumentativos, a fim de desenvolverem sua criticidade por meio da competência escritora. Porém, eles fariam isso de um modo diferente: usando seus celulares e smartphones.

Claro que os alunos continuariam a escrever textos manuscritos, porém, simultaneamente postariam comentários e debateriam sobre diversos temas em um aplicativo de celular. Inserir a tecnologia na Produção de Textos traz uma contribuição excelente para o processo de ensino e aprendizagem das múltiplas linguagens. Ao ficar somente no texto impresso, há tendência a uma análise voltada somente para os textos verbais. Por outro lado, a Internet propiciou a intensificação no uso de hipertextos e textos multimodais, sendo que esses termos se referem à relação entre 
diversos textos no meio digital e aos recursos audiovisuais integrados a eles. Há vários motivos para trabalhar com os textos do gênero digital, pois, segundo Marcuschi (2005, p.14):

Seu uso está em desenvolvimento e cada vez mais generalizado, suas peculiaridades formais e funcionais, não obstante têm contraparte com gêneros prévios e a trazem possibilidade de oferecerem uma revisão nos conceitos tradicionais, permitindo repensar nossa relação com a oralidade e a escrita. Assim esse discurso eletrônico constitui um bom momento para se analisar os efeitos das tecnologias na linguagem e o efeito da linguagem sobre elas.

Levando em conta a afirmação acima, não é à toa que as novas tecnologias são denominadas de TIC - Tecnologias da Informação e da Comunicação. Elas estabelecem novos métodos de comunicação e interação entre as pessoas. Portanto, uma vez que a interação tem papel importante na produção de linguagens e na formação do indivíduo, selecionou-se um aplicativo muito famoso entre os adolescentes para a execução do trabalho: o Whatsapp. Trata-se de um aplicativo de comunicação online instantânea, sem limite de caracteres, que também permite o envio de vídeos, fotos e áudio. Sem contar que os adolescentes o utilizam constantemente.

Depois de escolhido o aplicativo, criou-se um grupo de conversas em cada uma das turmas dos oitavos e nonos anos, totalizando seis turmas. O objetivo era tornar esse grupo um espaço para exposição de opiniões, e discussão de diversos temas, sem perder de vista as técnicas aprendidas em sala de aula. O professor era o administrador dos grupos e mediava as discussões e debates por meio de um aparelho exclusivo para isso.

Nos oitavos anos, a discussão girou em torno de um conteúdo visto na disciplina de Geografia: hegemonia norte americana. Os alunos deveriam discutir a respeito do seguinte questionamento: a hegemonia americana foi benéfica ou prejudicial à sociedade? Num primeiro momento os alunos deveriam formular suas teses acerca do tema e enviá-las pelo whatsapp, para que assim, pudessem descobrir quais colegas tinham um posicionamento diferente ou semelhante ao deles.

Feito isso, a discussão começou e em uma semana, os oitavos anos já tinham feito mais de duzentas postagens, em sua maioria, pequenos textos em que expunham suas teses e argumentos.

Com os nonos anos o procedimento não foi diferente, todavia os temas foram 
outros: racismo e desigualdade social. Especialmente os alunos desses anos têm um prazer nato em construir textos argumentativos, porém Ihes faltava técnica e estratégias de leitura que permitissem seu desenvolvimento. O nível de reflexão em seus comentários surpreendeu os professores, pois estavam além do esperado para a idade. Por exemplo, os comentários faziam relação com conceitos da Filosofia e com a situação política em que vivíamos, as eleições.

Ao tratar desses assuntos, os alunos, além de adquirirem habilidades de leitura e escrita, construíam aquilo que Zabala (2010) designou como conteúdos atitudinais, adotando comportamentos éticos e responsáveis diante das relações sociais. Em relação ao racismo e à desigualdade, por exemplo, colocaram em prática a alteridade, o respeito pela diversidade cultural e racial, dentre outros conceitos importantes para a vida em comunidade em situações do cotidiano ao visitarem um lar de crianças carentes na cidade, propiciando momentos de descontração e formação enquanto seres humanos. Muitos dos educandos mencionaram que lembraram das discussões pelo whatsapp ao lidarem com as crianças do lar e conhecerem cada uma de suas histórias, especialmente, no momento em que deveriam reagir aquilo que as crianças faziam ou lhes falavam.

Ao final das discussões, os alunos postaram um texto dissertativo-argumentativo em um ambiente de aprendizagem virtual, a Plataforma Blackboard. A rede de colégios em questão começou a utilizar a plataforma como forma de fomentar o uso da tecnologia na escola. Por meio dessa ferramenta, alunos e professores participaram de uma nova dinâmica para entrega e correção dos trabalhos, uma vez que todo esse processo tradicional de avaliação de trabalhos começou a ser feito nesse ambiente.

Os resultados do projeto foram muito positivos. A participação dos alunos nas aulas de Redação aumentou significativamente. A exposição de opiniões durante as aulas de outros componentes curriculares foi algo que chamou a atenção de outros professores.

Mas o grande ponto positivo pôde ser percebido por meio dos resultados das avaliações. Apesar dos números não serem os resultados de maior significado e importância, eles podem representar de forma concreta o que se conseguiu, ou não, alcançar.

Antes do projeto, os alunos não viam tanta importância em produzir textos e acreditavam que não era necessário ter hábito de estudo e leitura para a construção 
textual. Com isso, as dificuldades foram surgindo, ainda mais que o gênero trabalhado em sala contemplava uma tipologia completamente nova. O projeto foi importante para que os alunos se apropriassem de habilidades que os levariam a desenvolver a competência relacionada às diversas produções de linguagens. Junto a algumas outras ações, o projeto Eu sou o escritor do Whatsapp contribuiu para que o número de alunos em recuperação depois da execução do trabalho diminuísse em média 50\% em cada uma das turmas.

Com certeza, isso trouxe satisfação para o trabalho do professor e da escola que comprovou o que menciona Bunzen (2006, p.158) "aprende-se a escrever (assim como a falar) na relação com o outro, atualizando formas relativamente consagradas de interação linguística. Aprende-se a escrever por meio da interação verbal (em contextos formais e informais) e do uso do gênero"

Foi um projeto gratificante que conseguiu vencer o grande desafio da escola de hoje: aliar tecnologia à sala de aula, a fim de formar cidadãos competentes para a vida em sociedade e para a solução de problemas.

\section{CONCLUSÃO}

Inovar e criar constantemente. Assim deve ser o processo de ensino e aprendizagem atual. Modelos tradicionais de ensino não devem ser descartados, mas não devem ser encarados como a chave para o sucesso na educação. O projeto Eu sou o escritor do Whatsapp veio para provar isso.

Foram experimentadas várias formas de apreender e empregar os conhecimentos das aulas de Produção de texto, em especial as Tecnologias da Informação e Comunicação. Os resultados mostraram que os procedimentos adotados conseguiram levar a prática educativa à tão almejada aprendizagem significativa. Essa metodologia propiciou como Zabala (2010) opar destaca como fundamental, uma aprendizagem dos conteúdos a partir de uma vertente funcional, não uma mudança radical no conteúdo.

Ainda há muito avançar no campo do ensino associado à Tecnologia, mas o projeto foi essencial para motivar ainda mais a busca por novos caminhos para uma educação realmente eficaz.

\section{REFERÊNCIAS}

AROCENA, R. Riesgo, cambio técnico y democracia en el subdesarrollo. In: LUJÁN, J.L.; ECHEVERRÍA, J. Gobernar los riesgos: ciencia y valores en la sociedad del 
riesgo. Madrid: Biblioteca Nueva, 2004. p.207- 223.

BASTOS, J.A.S.L.A. (Org.). Tecnologia e interação. Curitiba: CEFET-PR, 1998.

BRASIL. Ministério da Educação. Parâmetros curriculares nacionais: terceiro e quarto ciclos do ensino fundamental. Secretaria de Educação Fundamental - Brasília: MEC, 1998.

BUNZEN, C. Da era da composição à era dos gêneros: o ensino de produção de texto no ensino médio. In: BUNZEN, C.; MENDONÇA, M. (Org.). Português no ensino médio e formação do professor. São Paulo: Parábola, 2006.

MARCUSCHI, L.A. Hipertexto e gêneros digitais: novas formas de construção do sentido. Rio de Janeiro: Lucerna, 2005.

RODRIGUES, N. Por uma nova escola: o transitório e o permanente na educação. São Paulo: Cortez, 1992.

ZABALA, A. A prática educativa: Como ensinar. Porto Alegre: Artmed, 1998.

ZABALA, A. Como ensinar e aprender competências. Porto Alegre: Artmed, 2010. 